Perspectiva Geográfica

ISSN 0123-3769

Vol. 15/2010; pp. 177-200

\title{
Cambios espaciales y su influencia en la configuración territorial de Aguazul y Tauramena 1974 2005
}

Spatial changes and their influence in the territorial configuration of Aguazul and Tauramena 1974 2005

Claudia Yolima Devia Acosta*

\section{Resumen}

El estudio aborda los principales cambios espaciales que influyen en la configuración territorial de los municipios de Aguazul y Tauramena (Casanare, Colombia) entre 1974y 2005. Se trata de un trabajo descriptivo de perspectiva temporal, que aborda los cambios visibles y los factores económicos, demográficos y sociales que influyeron en ellos. Se recurre a una periodización basada en el cambio en las actividades económicas y en los cambios político administrativos en la configuración territorial de estos municipios. El artículo centra el análisis en la influencia de la actividad petrolera en la región, y en su capacidad directa e indirecta de transformar el territorio.

Palabras clave: Cambio espacial, configuración territorial, territorialidad, petróleo.

* Magíster en Geografía. Investigadora Instituto de Estudios Sociales Contemporáneos IESCO, Universidad Central. ydevia@gmail.com 


\section{Abstract}

The study approaches the principal spatial changes that influence the territorial configuration of the municipalities of Aguazul and Tauramena in Casanare, Colombia between 1974 and 2005. It is a descriptive work of temporary perspective that approaches the visible changes and the economic, demographic and social factors that influenced these. It is appealed to a chronology based on the economic activities and the political and administrative changes in the territorial configuration of these municipalities. It is emphasized in the influence of the petroleum activity in the region and his direct and indirect aptitude to transform the territory.

Key words: Spatial Change, Territorial Configuration, Territoriality, Oil. 


\section{Introducción}

Según Sack y Raffestin (citados en Haesbaert, 2004), la configuración territorial es un proceso y un resultado de interrelaciones de poder entre múltiples actores, y se refleja en cambios espaciales, formas de control, morfología espacial y social. En tanto proceso, la configuración territorial de los municipios de Aguazul y Tauramena (Casanare) se relaciona con la conformación de ejes de poblamiento y de actividad social y económica asociados a dos reconocidos "centros petroleros" y a la transformación del espacio material y social a través de relaciones cotidianas que se asumen en formas de narración, acción y transformación sobre el territorio. Es necesario reconocer los cambios espaciales y poblacionales para analizar la configuración territorial de estos municipios, que tienen en común la existencia de una dinámica particular ligada a la existencia, valoración y disputa de un recurso estratégico como el petróleo. Se relacionaron algunos elementos visibles en el espacio: la conformación de la malla urbana y la reconformación urbana y veredal, la influencia de las vías como ejes morfológicos de la ocupación del espacio, de conexión de lo rural y lo urbano (Capel, 2000), así como en la redefinición de divisiones y realinderamientos en el territorio. Esto se constituye en sustento para leer los procesos reconfiguración del territorio de los municipios considerados.

Autores como Gramling y Brabant (1986) y Garcés (2003) han expuesto algunos modelos de escenarios centrados en lo urbano y asociados a actividades extractivas. Los primeros acuñaron el concepto de "Boomtown", referente a los escenarios urbanos que surgen junto a las actividades de generación de energía y explotación gasífera y petrolera; las "boomtowns" se distinguen por un rápido crecimiento de la población, causado por las oportunidades de empleo, que implica un componente de impacto socioeconómico y ambiental. En su trabajo, Garcés expone el modelo de las "Company Towns", asociadas a la explotación del cobre en Chile y descritas como "modelos urbanísticos alternativos que asumen la función de la fábrica, con el fin de la máxima eficiencia productiva, creando un modelo monocultural sin rupturas socioeconómicas" (Garcés, 2003:2). Estas características supondrían un reflejo en la morfología social y urbana, por eso se propone la descripción de los cambios espaciales más relevantes en los dos municipios y la indagación por los elementos que influyen en estos cambios como parte de la configuración territorial. Dada esta perspectiva, el artículo busca responder a los siguientes interrogantes: ¿cuáles son los principales cambios en el espacio geográfico de los municipios de Aguazul y Tauramena entre 1974 y 2005?, ¿cuáles elementos influyen en el cambio espacial a nivel urbano y veredal? y ¿cuál fue la influencia de la actividad petrolera en la generación de una organización espacial particular?

\section{Problema}

Las dinámicas demográficas y de cambio espacial se relacionan estrechamente 
entre sí y con la dinámica impuesta por las actividades económicas que se desarrollan a nivel territorial. La principal actividad económica de Aguazul y Tauramena ha sido la ganadería extensiva y, posteriormente, la agricultura. La ganadería demanda poca mano de obra y requiere de grandes extensiones de tierra (entre $10.000 \mathrm{y}$ 100.000 ha o más), lo que ha redundado en la creación de zonas de "vacío" demográfico; por eso en los lugares donde se concentra la hacienda ganadera, como Bolívar, Casanare y Caquetá, no se han generado procesos de concentración de población, y los sistemas urbanos han sido reducidos (Novoa, 2010). La actividad agrícola, aunque puede requerir de más mano de obra, tampoco genera concentraciones de población significativas. Los casos aquí expuestos se habían distinguido hasta los años noventa por una mayor ocupación rural (Tabla 2), pero con los hallazgos petroleros de Cusiana y Cupiagua el panorama territorial cambió drásticamente. La actividad petrolera, según la fase de desarrollo y producción en que se encuentre, requiere un número variable de mano de obra (calificada o no), y en vista de la baja oferta de esta en la región, sumada al carácter de "bonanza" asociada a los rumores de los altos salarios, se convierte en un "imán" para la población nacional, planteando la relación entre migración y actividad extractiva.

El rápido crecimiento demográfico, asociado al cambio económico y políticoadministrativo en las zonas de extracción de hidrocarburos, tiene una fuerte influencia en el cambio espacial y en la configuración territorial a nivel local y regional. Esto se hace más evidente con la actividad petrolera, pues es una de las que mayor capital maneja en el mundo a través de empresas privadas, de mayor interés para los Estados por la generación de ingresos directos y regalías que influyen de manera contundente en la transformación del territorio, y de interés para las personas que habitan ose desplazan a las zonas de producción por el flujo de dinero y las oportunidades laborales asociadas a esta actividad.

\section{Descripción del lugar}

Los municipios de Aguazul y Tauramena están ubicados en la franja comúnmente denominada "Corredor Petrolero" del departamento de Casanare, en la región de la Orinoquía colombiana, al oriente de la nación. El corredor petrolero se caracteriza por encontrarse en zona de transición entre la cordillera Oriental, en su vertiente oriental, y la llanura, con alturas que van entre 400 y $1500 \mathrm{msnm}$, con buenas condiciones de fertilidad y zonas pendientes.

El municipio de Aguazul se encuentra en la región central del Casanare; limita al norte con los municipios de Pajarito (Boyacá) y Recetor (Cas.); al sur, con Tauramena y Maní (Cas.); al oriente, con Yopal, y al occidente, con Tauramena y Recetor (Cas). Ocupa un área de 1.330 $\mathrm{km}^{2}$ entre el piedemonte de la cordillera Oriental y las sabanas del margen izquierdo de la cuenca del río Meta, que 
a su vez pertenece a la cuenca del Orinoco (Alcaldía de Aguazul, 2000).

Tauramena se encuentra al suroccidente del departamento de Casanare; cuenta con 247.249 ha y se encuentra entre los 160 y 2000 msnm. Limita al norte con los municipios de Chámeza y Recetor y el departamento de Boyacá; al oriente, con el municipio de Aguazul, estando separados por el río Cusiana, y con el municipio de Maní; por el sur, con aguas del río Meta y con el departamento del Meta, y por el occidente, con los municipios de Monterrey y Villanueva (Alcaldía de Tauramena-Unitrópico, 2000).

Los dos municipios se ubican entre paisajes de piedemonte y llanura, principalmente, y una pequeña franja de paisaje de montaña en la parte alta, por encima de los $1000 \mathrm{msnm}$; en zonas que colindan con el departamento de Boyacá y los municipios de Chámeza y Recetor (Casanare) presentan un paisaje escarpado, con crestas y lomas, de climas muy frío, húmedo y medio, con una alta pluviosidad. El paisaje de piedemonte está entre los 500 y 1000 msnm, es una franja que se extiende de sur a norte en la zona occidental del departamento, y es zona de transición entre montaña y llanura con influencia sobre las áreas de nacimiento o recarga hídricas de las microcuencas. El paisaje de llanura se compone de planicies entre $500 \mathrm{msnm}$ al occidente y $100 \mathrm{msnm}$ al oriente del departamento; está conformado por la acumulación de materiales de arrastre y de depositación de los ríos (IGAC, 1999:28-34).
La zona tiene como referencia hidrológica al gran río Orinoco, como principal corriente hídrica de orden regional; le sigue el río Meta, como cuenca de orden subsiguiente; luego el río y la cuenca del Cusiana, que nace en la cordillera Oriental, en el departamento de Boyacá, con una longitud de $365 \mathrm{~km}$, de los cuales solo $115 \mathrm{~km}$ son navegables. A esta cuenca pertenecen las subcuencas de los ríos Charte, Unete y Chitamena, que cruzan los municipios de Aquitania, Labranza Grande y Pajarito, en Boyacá, y Recetor, Aguazul, Tauramena y Maní, en Casanare, y se distinguen por su aptitud agrícola y ganadera, además de la explotación petrolera (IGAC, 1999: 65-69).

\section{Metodología}

Milton Santos (2000) propone la elaboración de una periodización a escalas menores o "tiempo espacial”, pues todos los espacios son cronológicamente diferentes y están cargados de diferentes significaciones. Desde la morfogénesis se propone hacer un estudio diacrónico (histórico) que muestre las interrelaciones entre elementos que den cuenta de las transformaciones del paisaje (Capel, 2002). Para eso se propone una periodización en tres etapas diferenciadas por criterios de producción económica y cambios político-administrativos con gran impacto en el cambio social y espacial de la población. El primer momento, de 1974 a 1985, muestra un escenario "sin petróleo", donde Casanare se restablece como Intendencia y deja de ser provincia de Boyacá. De 1985 a 1999 se observa el inicio de las actividades exploratorias y 
el auge de la producción. El decaimiento sostenido de la producción petrolera marca el inicio del tercer momento (2000), en el cual se mantiene y se eleva el crecimiento de la población, lo cual se refleja en el censo de 2005.

Esta investigación se aborda desde una metodología cualitativa, sin ignorar que la integralidad del análisis de la configuración territorial requiere de referencias a datos cuantitativos. Se usó información secundaria obtenida en campo, en archivos centralizados en Bogotá y en documentos locales concernientes a la historia, actividades económicas, lineamientos jurídicos y demografía, entre otros. Se revisaron los censos DANE de 1973 a 2005 , Esquemas de Ordenamiento Territorial, anuarios estadísticos, planes de desarrollo y archivos del Concejo. La información cuantitativa fue integrada al trabajo directamente y se recurrió al análisis básico de tendencias poblacionales y tasas de crecimiento geométrico $^{1}$, y a la construcción del índice de densidad poblacional, para ver la razón o relación entre el número de habitantes por $\mathrm{km}^{2}$ en una entidad territorial $\left(\mathrm{hab} / \mathrm{km}^{2}\right)$.

En el trabajo de campo se hizo uso de la etnografía sistemática, basada en unos ejes de observación propuestos previamente: historia de ocupación, cambios en el paisaje, cambios en la conformación urbana e influencia social y espacial de la actividad petrolera. Se usaron instrumentos cualitativos como la entrevista semiestructurada, la entrevista en profundidad y la historia de vida (tres habitantes antiguos por municipio). Para el rastreo de cambios en forma y tamaño de los núcleos urbanos de Aguazul y Tauramena, del establecimiento de nueva infraestructura y de cambios espaciales, previo a campo se hizo fotointerpretación por estereoscopía de las fotografías aéreas de diferentes periodos (tabla 1), para denotar cambios en los bordes urbanos, tendencia de crecimiento $\mathrm{y}$ densificación; de estas se escogieron las de mejor resolución, encuadre y significancia para cada periodo. Posteriormente se digitalizaron los resultados y se mudaron al programa Arc Gis 9.2. Los resultados de la fotointerpretación se georreferenciaron con base en los datos de la Geodatabase suministrada por el IGAC, y se crearon polígonos por área urbana y año; se calculó el área de los polígonos, se superpusieron sobre las fotografías aéreas. También se tomaron los mapas urbanos de los EOT de cada municipio (2000 para Aguazul y 2005 para Tauramena), se migraron a formato shape en ArcGis para incluirlos en la comparación.

El crecimiento geométrico o exponencial supone un crecimiento porcentual constante en el tiempo, es aplicable a periodos largos. Desde el punto de vista demográfico se identifica con el comportamiento real de la población y con el cambio en área urbana y construida. $\left(\left((A f / A i)^{\wedge}(1 / 20)\right)-1\right)^{\star} 100=3,3 \%$.Donde $A f=$ último año del periodo se divide en $A i=$ dato del primer año, ese resultado se eleva a la diferencia de años que hay en el periodo y a todo ese producto se le resta uno (1) y se multiplica por cien.

182 Claudia Yolima Devia Acosta 
Tabla 1. Fotografías aéreas utilizadas

\begin{tabular}{|c|c|c|r|l|r|}
\hline Municipio & Año & Sobre & \multicolumn{1}{|c|}{ Fotos } & Fecha & Esc. aprox. \\
\hline & 1955 & $139 \mathrm{~B}$ & $4035,4036,4037$ & feb-26 & $1: 60.000$ \\
& $1970^{*}$ & sf & sf & sf & sf \\
& 1988 & 34478 & $00,01,02,03,04$ & ene-06 & $1: 23.300$ \\
& 1992 & 36407 & $227,228,229,230$ & sep-24 & $1: 40.300$ \\
AGUAZUL & 2003 & 38896 & $38,139,140$ a 14 & oct-04 y 06 & $1: 11.800$ \\
& 1978 & 29301 & 20 a 23 & feb-14 & $1: 32.600$ \\
& 1981 & 30785 & 0028 a 0030 & ene-25-30 & $1: 41.400$ \\
& 1995 & 37127 & $81,83,84$ & feb-10 & $1: 45.500$ \\
\hline \multirow{4}{*}{ TAURAMENA } & 1995 & 37127 & $80,81,83$ & feb-10 & $1: 45.500$ \\
& 2003 & 38897 & 152,153 & oct-04 y 06 & $1: 12.000$ \\
& 2003 & 38897 & 150,151 & oct-04 y 06 & $1: 12.000$ \\
\hline
\end{tabular}

Se articularon al análisis los conceptos de área urbana, que corresponde a una línea que separa en teoría la zona urbana de las zonas rurales del municipio que pueden ser susceptibles de ser urbanizadas y que no deben sobrepasar las áreas con disponibilidad de servicios públicos (Art. 31 Ley 388 de 1997), y área construida, es decir, donde se ha construido sobre zonas parceladas, muy asociada a la densidad poblacional y de construcción, con usos de suelo de naturaleza no agrícola.

Se hizo uso de algunos de los métodos de la morfología urbana, como apoyo para comprender el proceso de reconfiguración territorial de estos dos municipios. Se reconoció la conformación de las áreas urbanas, sus particularidades, cambios históricos y procesos reflejados en el plano, apoyándose en las fotografías aéreas, a escala entre 10.000 y $12.000 \mathrm{~cm}$, aproximadamente. Se observaron los planos, el uso del suelo, las vías principales, la localización de los núcleos urbanos y sus etapas de crecimiento. Las fotografías también sirvieron de apoyo en la realización de las entrevistas, como forma de representación del espacio, que permitió recordar aspectos relevantes de cambio. A lo largo del trabajo de campo se compiló material fotográfico histórico y en tiempo real sobre aspectos espaciales y económicos de los dos municipios, que aportan un apoyo perceptivo de los cambios sociales y espaciales denotados en el texto.

\section{Antecedentes históricos}

En 1654, Tauramena era conocido como San Guillermo de Sabana Alta, luego fue denominado Barro Blanco; inicialmente dependía de Santiago de las Atalayas, y luego se consagró como caserío y dependió de Chámeza. Su estructura urbana se inició aproximadamente en 
1897, con el establecimiento de unas viviendas en tierras municipales y la parcelación de propiedades agrícolas. En 1944 se constituyó en residencia de misioneros, y en 1946 se establecieron las religiosas misioneras hijas de Santa Catalina y de María Inmaculada (Hermanas Lauritas), por lo que se distinguió entre la red regional por ser centro educativo al que se llegaba por vía aérea. El municipio fue creado por la Asamblea de Boyacá mediante la ordenanza jurídica 29 del primero de diciembre de 1962. Se configuraron barrios aisladamente, que fueron conformando un tejido urbano continuo; con el tiempo se empieza a generar una retícula ortogonal conformada por calles y carreras organizadas en torno al actual sector del Parque Los Fundadores y la carrera 13, conformando el área más antigua del municipio, donde aún permanecen construcciones con importante valor histórico, como la iglesia de San Cayetano, el colegio Nuestra Señora de la Consolación, la casa del señor Ignacio Torres y las viviendas ubicadas sobre la carrera 13 , entre otras. Hasta 1970 solo se encontraba consolidado el barrio Centro, que en 1973 ya contaba con agua potable.

Aguazul se constituye como municipio por el decreto 295 del 19 de julio de 1954 de la Gobernación de Boyacá. Antes de esta fecha se encontraba al margen contrario del río y se conocía como Sevilla, un pequeño pueblo de paso con unas pocas casas en madera; pueblo de liberales que fue quemado en la época de "la Violencia". En el mismo decreto,
Monterrey y Aguazul eran nombrados inspecciones de policía bajo la jurisdicción de Tauramena. El nuevo asentamiento se fundó en 1950, y el trazado de sus primeras calles se hizo el 4 de abril de 1954, siguiendo como modelo un entramado de damero. Se determinó el lugar de la plaza principal con base en el cruce de caminos que salían para Sogamoso y para un pozo azul que se formaba en el río Unete, el cual desapareció en 1970 con el desvío del curso del río, y fue la inspiración para bautizar el nuevo asentamiento como "Aguazul". Las calles que estructuraron el área urbana fueron desde un principio la salida para Maní y la vía por donde se comunicaba el pueblo con Sogamoso, hoy avenida Antonio Bernal Pinzón (Figura 1). Por medio de estas llegaban las recuas de mulas de los arrieros con productos con los que comerciaban en el pueblo.

\section{Periodización de Aguazul}

\section{a. 1974-1985}

En 1973, la población de Aguazul era de 8.012 personas, de las cuales el $67,6 \%$ estaban asentadas en su zona rural. A finales de los años sesenta se dio paso al cultivo del arroz; se reconoce en este periodo la pujanza de este sector a través de sus agentes, cultivadores, propietarios e instituciones gremiales asociadas al fomento de esta actividad agropecuaria. La actividad arrocera demandó mano de obra, lo que permitió en un primer momento un mesurado crecimiento de población, que, aunque mantiene relación con el sector rural, empieza a asentarse 
en la creciente área urbana. La primera malla vial se conocía como el "Sural" (ver Figura 1). La zona del centro, donde se ubican el parque central, la iglesia y el edificio de la alcaldía, se construyó en terrenos donados por un particular. $\mathrm{La}$ forma de la malla estuvo desde un inicio orientada por los tres grandes accesos a este centro: las vías que comunican con Sogamoso, con Yopal (posteriormente Marginal del Llano) y con Maní, las cuales son diagonales en el contexto del tejido vial interurbano. Estas vías, en especial la que comunica con Sogamoso, se constituyeron en los principales ejes de movimiento de flujos de bienes, personas y servicios, además de la pista aérea, pues cada municipio contaba con la propia para el transporte de personas $\mathrm{y}$ bienes.

La trama urbana es cuadrangular, con mayor densidad de edificaciones cerca al parque central, es decir, hacia el costado suroccidental. En este se encuentra un área de transición entre las primeras calles y la ronda del río Unete, que funciona como barrera natural para el crecimiento urbano (Alcaldía de Aguazul, 1999). Esta demarcación se mantiene durante este periodo sin cambios significativos.

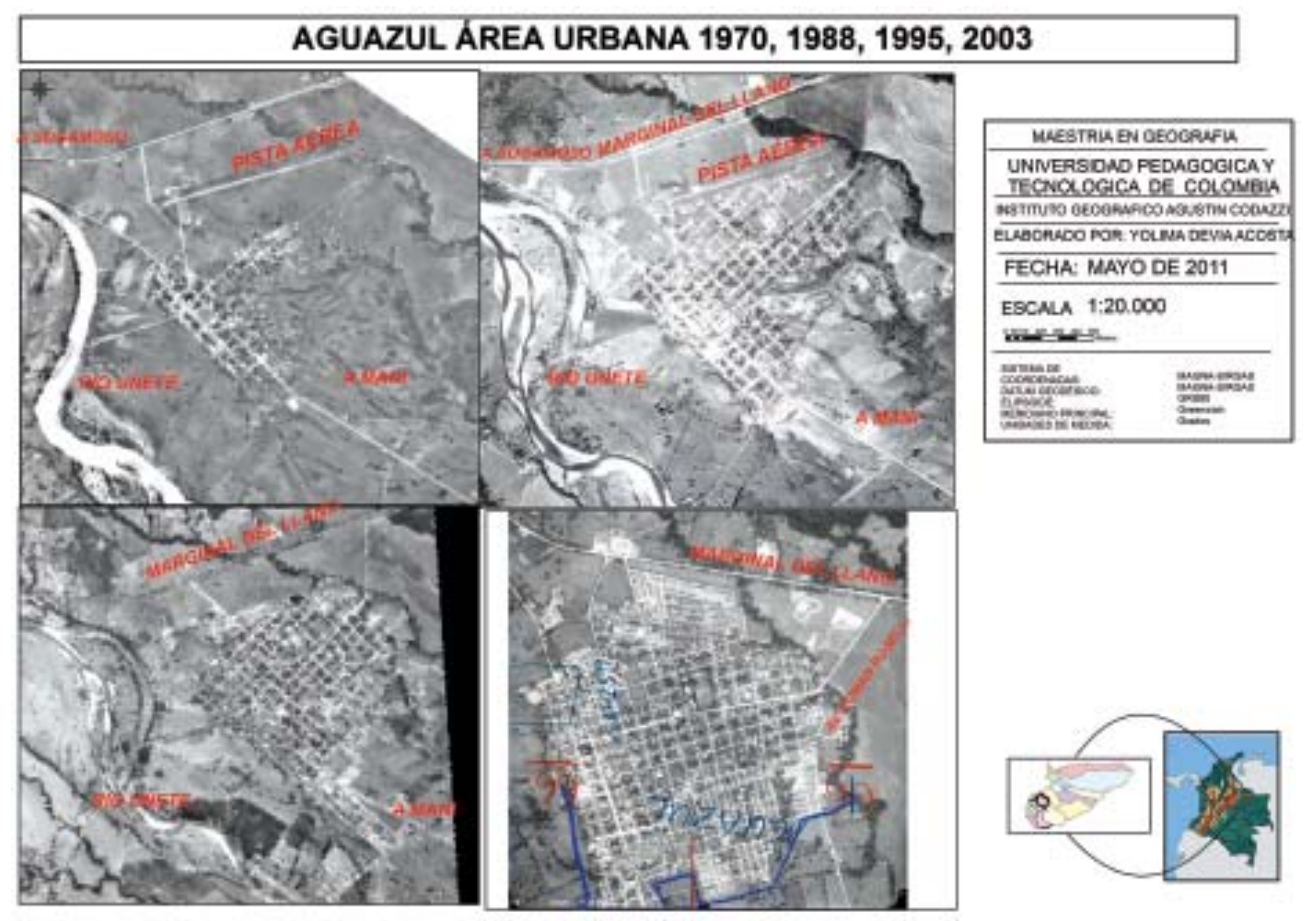

Figura 1. Fotografías aéreas de Aguazul, 1970, 1988, 1995 y 2003

Fuentes: Oficina de planeación Aguazul e IGAC. 
Tabla 2. Población por área de residencia

\begin{tabular}{|c|l|r|r|r|r|}
\hline \multicolumn{1}{|c|}{ Municipio } & & $\mathbf{1 9 7 3}^{*}$ & $\mathbf{1 9 8 5}$ & \multicolumn{1}{c|}{1993} & \multicolumn{1}{c|}{$\mathbf{2 0 0 5}$} \\
\hline \multirow{3}{*}{ Aguazul } & Urbana & 2.578 & 5.060 & 8.674 & 20.411 \\
& Rural & 5.434 & 9.555 & 4.082 & 7.916 \\
& Total & 8.012 & 14.615 & 12.756 & 28.327 \\
\hline \multirow{3}{*}{ Tauramena } & Urbana & 621 & 1.016 & 2.660 & 10.153 \\
& Rural & 4.567 & 5.877 & 3.222 & 6.086 \\
& Total & 5.188 & 6.893 & 5.882 & 16.239 \\
\hline \multirow{3}{*}{ Yopal } & Urbana & 4.550 & 16.351 & 33.790 & 90.218 \\
& Rural & 5.594 & 13.356 & 10.971 & 16.604 \\
\hline \multirow{2}{*}{ Casanare } & Total & 10.144 & 29.707 & 44.761 & 106.822 \\
& Urbana & s.d & 47.636 & 86.553 & 200.952 \\
& Rural & s.d & 99.838 & 71.596 & 94.401 \\
& Total & s.d & 147.474 & 158.149 & 295.353 \\
\hline
\end{tabular}

Fuente: Censos DANE.

* En 1973 Casanare era provincia de Boyacá, por lo cual no se discrimina como entidad territorial en los Censos anteriores a 1985.

En 1982, el municipio contaba con "los servicios mínimos”. El centro urbano empezó a recibir el suministro de agua en 1975 y se completaron las redes de distribución a finales de los años ochenta. Hasta entonces se habían constituido tres barrios: Centro, Jorge Eliécer Gaitán y Sevilla. En ese entonces se accedía a la tierra por adjudicación, más que por un intercambio económico; las personas podían solicitar directamente al personero del municipio la adjudicación de un lote para vivienda; recibían lotes de 40 x 40 o 50 x 50, en los cuales se construía la vivienda y se dejaba un espacio de solar para tener frutales y un pequeño cultivo de autosostenimiento (entrevista 21, funcionario de Planeación Municipal, com. per.).

\section{b. 1985-1999}

Entre 1973 y 1985 la población creció un $5,1 \%$, y si bien se empezó a notar una tendencia de mayor crecimiento de la población urbana, aún lo población se concentraba significativamente en la zona rural (ver Tabla 3).

Tabla 3. Aguazul - Tasa de crecimiento de población por zona de residencia (Crecimiento geométrico promedio anual)

\begin{tabular}{|c|c|c|c|c|c|c|}
\hline Censo & Urbana & \% Urbana & Rural & \% Rural & Total & \% Total \\
\hline 1973 & 2.578 & & 5.434 & & 8.012 & \\
1985 & 5.060 & 5,8 & 9.555 & 4,8 & 14.615 & 5,1 \\
1993 & 8.674 & 7,0 & 4.082 & $-10,1$ & 12.756 & $-1,7$ \\
2005 & 20.411 & 7,4 & 7.916 & 5,7 & 28.327 & 6,9 \\
$1973-2005$ & & 6,7 & & 1,2 & & 4,0 \\
\hline
\end{tabular}

Fuente: Cálculos propios basados en Censos Dane, 1973, 1985, 1993 y 2005. 
Desde 1988 se puede ver la tendencia de crecimiento del área urbana, siguiendo las calles del primer trazado, principalmente la vía que conduce a Maní y la Av. Román Roselli, pero sin que sean áreas completamente construidas (ver Figura 1). Es posible ver que muchos lotes de manzanas ya incorporadas a la red de servicios públicos no han sido construidos, y que los construidos, si bien mantienen la continuidad que marcan los parámetros trazados, no lo han hecho a partir de un plan de vivienda, sino predio a predio. En 1988 el área urbana era de 104,45 ha, aproximadamente (ver Tabla 5 y Figura 1), es decir, mayor en un $63 \%$, en comparación con la existente en 1970, y el área construida era de 85 ha, aproximadamente (Dureau y Maldonado, 1998).

Tabla 4. Área construida

\begin{tabular}{|c|c|c|c|}
\hline Año & $\begin{array}{c}\text { Superficie } \\
\text { construirda }\end{array}$ & $\begin{array}{c}\text { Superficie } \\
\text { aumentada }\end{array}$ & $\begin{array}{c}\text { Tasa anual } \\
\text { (Mz) }\end{array}$ \\
\hline 1970 & 35 & & \\
1988 & 87 & 52 & 24,55 \\
1992 & 100 & 13 & 89,88 \\
1999 & 120 & 20 & 53,41 \\
2003 & 262 & 142 & 245,20 \\
$1970-2003$ & & & 17,87 \\
\hline
\end{tabular}

Fuente: Cálculos propios basados en fotointerpretación.

En 1989 se distinguían los barrios Centro, Gaitán, Sevilla y Las Ferias (DANE, 1998:18), producto del loteo del suelo municipal. En este periodo la actividad exploratoria del petróleo era fuerte y empieza a crecer la población urbana, al punto que entre 1990 y 1994 surgen aceleradamente siete barrios (UN-CES,
2005: 15). Si bien continúa la adjudicación como forma de acceso a la tierra, las modalidades de urbanización empiezan a modificarse, aparecen procesos de invasión y construcciones comunitarias impulsadas por organismos gubernamentales y no gubernamentales. Es así como en 1990 se crea el barrio Carlos Pizarro, producto de la ocupación ilegal de predios, así como los barrios Oriente y Simón Bolívar, en 1993, y Porvenir, en 1994. En ese momento ya se conocía la dimensión de las reservas en los hallazgos de Cusiana y Cupiagua, y la proporción de población rural y urbana de 1973 se había invertido (ver Tabla 2) por llegada de numerosas personas, atraídas por el rumor de la actividad petrolera.

Tabla 5. Aguazul - Área urbana

\begin{tabular}{|c|c|c|c|}
\hline Año & $\begin{array}{c}\text { Área } \\
\text { urbana }\end{array}$ & $\begin{array}{c}\text { Área urbana } \\
\text { aument. (has) }\end{array}$ & $\begin{array}{c}\text { Área urbana } \\
\text { aument. (has) }\end{array}$ \\
\hline 1970 & 64,22 & & \\
1988 & 104,45 & 40,23 & 22,78 \\
1992 & 199,14 & 94,69 & 211,94 \\
1996 & 223 & 23,86 & 121,01 \\
1999 & 225 & 2 & 25,99 \\
2003 & 255,19 & 30,19 & 134,40 \\
$1970-2003$ & & & 17,25 \\
\hline
\end{tabular}

Fuente: Cálculos propios basados en fotointerpretación.

La fotointerpretación realizada sobre la fotografía aérea de 1992 demuestra que el área urbana era de 199,14 ha, aproximadamente (ver tabla 5), un $91 \%$ mayor que en 1988, y que existían 100 manzanas con edificaciones, $15 \%$ más que en el anterior periodo. En 1996, el área urbana ya alcanzaba las 223 ha, 
según los datos de Flórez et al. (1998), $12 \%$ más que en 1992, y un tamaño casi ocho veces mayor que en 1970, solo 26 años después. Este crecimiento se debe al asentamiento de personas que arriban en busca de oportunidades laborales, pues en 1996 se intensifica la demanda de mano de obra para la construcción de infraestructura petrolera, consistente en obras civiles como vías y trochas para la entrada de maquinaria, y la construcción de los $\mathrm{CPF}^{2}$, que ya habían iniciado en 1993. No en vano el mayor crecimiento de la población municipal es de 6,9\% promedio anual en el periodo 1993-2005 (ver Tabla 3).

\section{c. 1999-2005}

La afluencia de población se refleja en el índice de densidad poblacional, que se duplica entre 1993 y 2005, pasa de 86,2 a $191,4 \mathrm{hab} / \mathrm{km}^{2}$. El perímetro urbano en 1999 era de 912,78 ha, según Catastro, entre las cuales cerca de 225 ha $(25 \%)$ se encontraban urbanizadas y debidamente cubiertas por la oferta de servicios básicos. Sin embargo, la cantidad de las manzanas construidas en su totalidad eran 120; esto indica que menos de 90 ha, es decir, el $10 \%$ del área urbana, se encontraban densificadas (Alcaldía de Aguazul, 2000:147).

El principal problema asociado a la inmigración de personas era la oferta de vivienda, pues el municipio no contaba con terrenos propios para la ejecución de planes de vivienda de interés social. La construcción de nuevas áreas residenciales se inició en los últimos cinco años de este periodo en lotes periféricos del área urbana, especialmente en las periferias nor-orientales y sur-orientales, y recientemente se observa una tendencia a desarrollar nuevos proyectos sobre el área de influencia de la Avenida Marginal del Llano (ver Figura 1); en esta área se construyeron nuevas urbanizaciones como La Espiga y Villa del Río; esto se debe al reconocimiento del río Unete como barrera natural al crecimiento urbano (ver figura 1), al igual que la zona norte, de alta pendiente cruzando la vía Marginal del Llano (Dureau y Flórez, 2000: 58).

Dentro del área urbana hay algunas manzanas que, aunque hacen parte del trazado general que marca el Plan Vial, no se encuentran urbanizadas, convirtiéndose en una dificultad para el desarrollo urbano de la ciudad, ya que se encuentran varios lotes de propiedad privada que no habían podido ser adquiridos por la administración municipal para ser urbanizados, pues sus propietarios los mantenían en reposo (lotes de engorde). La ampliación de Aguazul se ha visto afectada por esta dificultad con la propiedad de la tierra, tanto en el centro como en la periferia del área urbana. En este periodo se intensificó la construcción tanto de

Center Production Facilities, en donde concentran la infraestructura y operaciones para separar gas y agua del hidrocarburo; posteriormente se concentra también la infraestructura habitacional de los trabajadores directos de la empresa, especialmente en el caso del CPF de Cusiana en Tauramena. 
infraestructura como de vivienda y de equipamientos urbanos gracias a la recepción de regalías (Figura 1). Se cuenta también con amplias coberturas en servicios públicos a nivel urbano y veredal. En el proceso de crecimiento y organización del área urbana se propició la ocupación de la zonas disponibles, se gestionaron planes de loteo y se legalizaron los barrios de invasión. El crecimiento urbano de Aguazul se refleja en el crecimiento del plano urbano, la densificación de la construcción y el crecimiento de la ocupación, pues $72 \%$ de la población está en el área urbana. Aun con esta particularidad, se reconoce en 2003 un área urbana de 255,29 ha y 262 manzanas construidas (Tablas 4 y 5, Figura 6).

\section{Periodización de Tauramena}

\section{a. $1974-1985$}

Aun conociendo la antigüedad de la ocupación de Tauramena, en 1973 solo el 1,2\% de la población se ubicaba allí en la zona urbana (Tabla 6). De menor tamaño y concentración poblacional (Aguazul le dobla en población), la población de Tauramena continúa siendo predominantemente rural.

Los primeros barrios de Tauramena se levantaron sobre terrenos entregados por el Incora y, luego, por la alcaldía municipal; se crean los barrios Centro, en 1970, y Jorge Eliécer Gaitán, en 1976; al tiempo se inicia un proceso de venta de terrenos sin servicios en zonas aún rurales, que son construidos individualmente por compradores sin títulos de propiedad. En 1978 se constituyen otros barrios que aún se mantienen: Primavera, parte de La Florida y de Los Libertadores. El área urbana comprendía unas pocas manzanas y el principal eje de comunicación era la pista aérea, que aún se encontraba fuera del área urbana (ver Figura 2). Respecto a las características de Tauramena en 1978, comenta un habitante originario:

... esto era una aldeíta muy bonita, el pueblito solamente era aquí, donde vemos a nuestra izquierda el parque, el parque que hoy se llama el parque Los Fundadores, y alrededor del parque estaba la iglesia, en estos momentos estamos aquí en el Palacio Municipal, pero esto en ese entonces era sabana, y

Tabla 6. Tauramena - Tasa de crecimiento de población por zona de residencia

(Crecimiento geométrico promedio anual)

\begin{tabular}{|c|c|c|c|c|c|c|}
\hline Censo & Urbana & \% Urbana & Rural & \% Rural & Total & \% Total \\
\hline 1973 & 621 & & 4.567 & & 5.188 & \\
1985 & 1.016 & 4,2 & 5.877 & 2,1 & 6.893 & 2,4 \\
1993 & 2.660 & 12,8 & 3.222 & $-7,2$ & 5.882 & $-2,0$ \\
2005 & 10.153 & 11,8 & 6.086 & 5,4 & 16.239 & 8,8 \\
$1973-2005$ & & 9,1 & & 0,9 & & 3,6 \\
\hline
\end{tabular}

Fuente: Cálculos propios basados en Censos Dane, 1973, 1985, 1993 y 2005. 
el aeropuerto incluso quedaba creo que más cerquita, después se fue corriendo, se fue corriendo, y hasta que desapareció porque ya finalmente aquí no hay aeropuerto (Entrevista 16. Funcionario de Planeación Municipal, Tauramena, com. per.).

En 1976 se empiezan a ver construcciones en Puente Cusiana, que si bien no pertenece a la zona urbana, se considera como barrio e importante núcleo de población en el cruce de la Marginal del Llano con la vía que conduce a Tauramena y a Monterrey, junto al río Cusiana, un paso obligado, en especial, para los ganaderos que realizaban sus travesías de llano y que como punto de cruce de caminos generaría su propia dinámica de concentración de población gracias a la actividad petrolera. A través de fotointerpretación se calcula que el área urbana en 1978 es de 25,7 ha, aproximadamente.

\section{b. 1985-1999}

El inicio de este periodo no muestra cambios notorios en la estructura urbana de Tauramena, se trata de un municipio principalmente agrícola, con un centro urbano modesto y aún con un mayor peso poblacional en la zona rural.

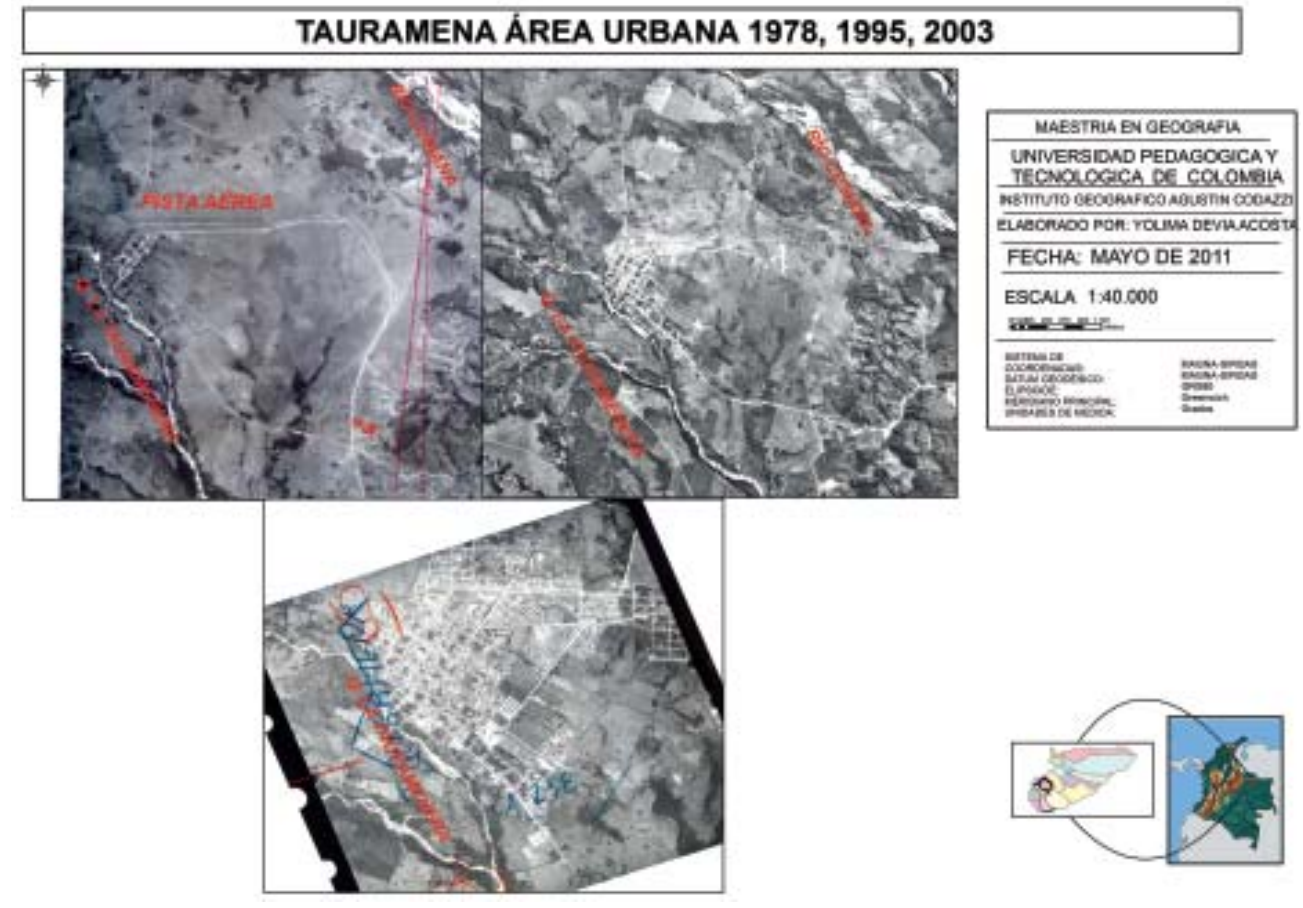

Figura 2. Fotografías aéreas deTauramena, 1978, 1995 y 2003 Fuente: IGAC. 
Alrededor de 1990 la administración municipal empezó a distribuir lotes en lo que correspondería a los barrios La Primavera y El Mastranto; en este la administración intervino con un plan de urbanismo y se creó una cooperativa que permitía entregar los cimientos y la conexión a servicios públicos e incluía la compra colectiva de materiales y organización comunitaria del trabajo. En 1991 se contaba con aproximadamente 30 ha urbanizadas (Dureau y Flórez, 2000: 58), y entre 1992 y 1995 se ve el surgimiento de los barrios Buenos Aires, Las Villas, Las colinas y Palmarito, y se completa La Florida. Prueba de la aceleración en la construcción urbana es que entre abril de 1993 y abril de 1994 la Alcaldía municipal expide 229 licencias de construcción (Dureau y Flórez: 58); el aceleramiento de la construcción sucede como respuesta a las migraciones $y$, por ende, al gran déficit habitacional que se dispara por el desarrollo de actividades petroleras en el municipio. Esto va de la mano con la creación del servicio de Planeación en 1992, y una mejora en la intervención de la administración municipal en la

Tabla 7. Tauramena - Área construida

\begin{tabular}{|c|c|c|c|}
\hline Año & $\begin{array}{c}\text { Superficie } \\
\text { construida }\end{array}$ & $\begin{array}{c}\text { Superficie } \\
\text { aumentada }\end{array}$ & $\begin{array}{c}\text { Tasa anual } \\
\text { (Mz) }\end{array}$ \\
\hline 1978 & 12 & & \\
1981 & 17 & 5 & 71,00 \\
1991 & 37 & 20 & 35,20 \\
1995 & 53 & 16 & 98,70 \\
2003 & 193 & 140 & 85,47 \\
$1978-2003$ & & & 23,11 \\
\hline
\end{tabular}

Fuente. Cálculos propios basados en fotointerpretación. urbanización desde 1993, que redunda en la puesta en marcha de programas de vivienda de interés social (VIS) desde 1995; de allí surgen Caribabare y Almendros, conocidos hoy como barrio La Cascada.

La recepción de regalías desde 1995 (Figura 3), derivadas de la explotación petrolera, influye notablemente en estos cambios en el espacio. En el gobierno de Gundisalvo López (1995-1997) se observó la mayor transformación de Tauramena, percibido en un cambio:

... de la aldea a un concepto ya más de pueblo organizado urbanísticamente, territorialmente [...] se planifico Tauramena, en desarrollo urbanístico, en alcantarillado fluvial, que creo que es uno de los pocos municipios que tiene alcantarillado fluvial, el alcantarillado sanitario, el acueducto municipal, otras obras de infraestructura de gran importancia como es el terminal de transportes, el coliseo, donde hoy funciona el INDERTA [Instituto de Deporte y Recreación del Casanare], la pavimentación... (Entrevista 16, Funcionario de la oficina de Planeación Municipal, Tauramena, com. per.).

Tabla 8. Tauramena - Área urbana

\begin{tabular}{|c|c|c|c|}
\hline Año & $\begin{array}{c}\text { Área } \\
\text { urbana (ha) }\end{array}$ & $\begin{array}{c}\text { Área } \\
\text { aumentada }\end{array}$ & $\begin{array}{c}\text { Tasa anual } \\
\text { (ha) }\end{array}$ \\
\hline 1978 & 25,70 & & \\
1981 & 36,41 & 10,71 & 120,41 \\
1991 & 47,00 & 10,59 & 26,62 \\
1995 & 107,10 & 60,10 & 178,43 \\
2003 & 217,70 & 110,60 & 80,08 \\
$1978-$ 2003 & & & 23,40 \\
\hline
\end{tabular}

Fuente. Cálculos propios basados en fotointerpretación. 
En 1995, el área urbana de Tauramena era de 107,1 ha; en 17 años creció 4,2, en comparación con 1978 (ver Figuras 2 y 7). Entre 1978 y 1996 se producen las transformaciones más notorias en las áreas urbanas del corredor petrolero. En 1995 se presenta la tasa de crecimiento urbana más alta: 15,03\% (ver Tabla 8), pues el área urbana creció en 60 ha entre 1991 y 1995. Al igual que en Aguazul, este crecimiento está asociado al levantamiento de la infraestructura petrolera, en especial la construcción del CPF de Cusiana, y a la afluencia de emigrantes que buscan vincularse laboralmente a las actividades petroleras.

\section{c. 1999-2005}

La tendencia de crecimiento urbano se mantiene en esta época hasta 2003, mientras se construyó y se terminó de montar la estructura del CPF, por la cantidad de mano de obra que se asentó temporalmente en la zona y que generó la inversión de los porcentajes de las poblaciones urbana y rural: mientras la primera aumentó, la segunda disminuyó (ver Tabla 6), además del drástico cambio de los ingresos e inversión municipales, gracias a las regalías.

Unos de los fenómenos particulares en la urbanización de Tauramena, ya mencionados, son la urbanización ilegal, la alta tendencia a la autoconstrucción, la diversidad en las viviendas y en sus características internas y la lógica especulativa sobre el suelo, que crecía mientras se iba asentando la actividad petrolera y creciendo el flujo migratorio. La alta demanda de vivienda generó la subdivisión de las viviendas, la predominancia de la vivienda tipo cuarto $\mathrm{y}$, en algunos casos, la vivienda tipo apartamento (e incluso la fragmentación de los hogares).

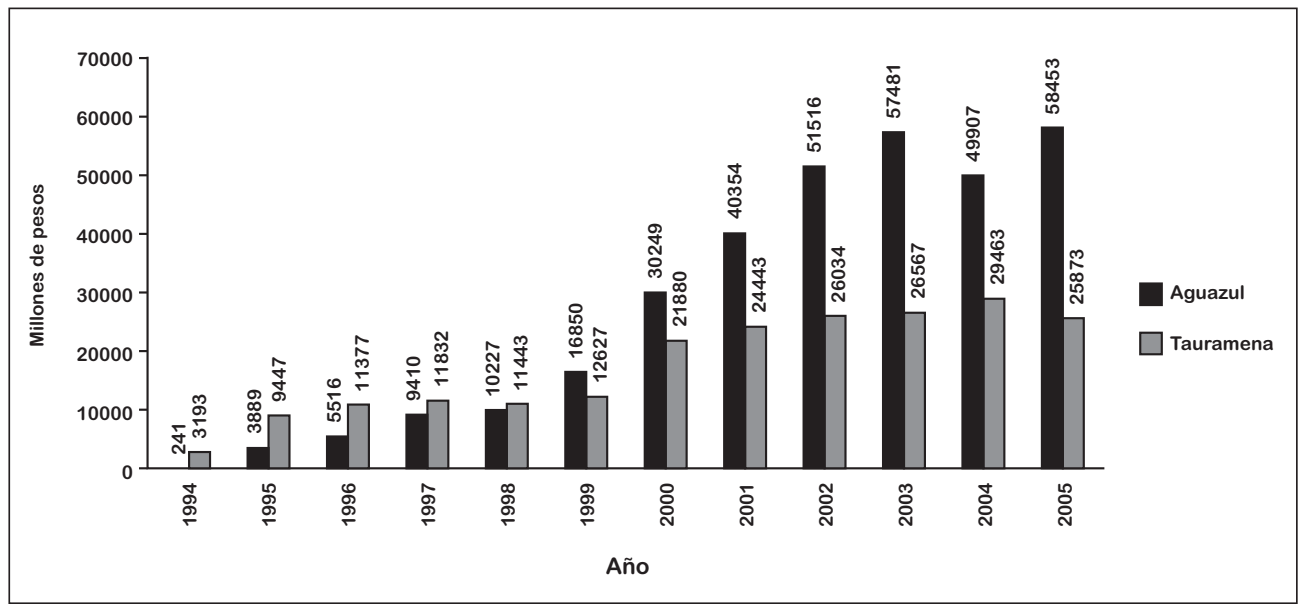

Figura 3. Histórico de regalías giradas a Aguazul y Tauramena, 1994-2005

Fuente: Ecopetrol - ANH.

192 Claudia Yolima Devia Acosta 
El área urbana en 2003 es de 217,7 ha, duplicando su crecimiento en 10 años, y 8,5 veces mayor con respecto a 1978 . Se puede apreciar el cambio del área urbana en términos de tamaño y forma entre los años de 1978, 1995 y 2003 (ver Figuras 2 y 7). Si bien la tasa de crecimiento del área urbana no es la más alta para este periodo $(13,83$ ha en relación con las 15,03 ha de 1995), sí lo es la tasa de crecimiento de las áreas construidas (ver Tabla 7): hay 140 manzanas más que en 1995, lo que indica una mayor significancia del fenómeno de densificación de la construcción que de la expansión urbana misma. Si se observa la fotointerpretación, es posible notar la tendencia a ocupar los espacios que aún quedaban sin construir, manteniendo el perímetro urbano de 2003 (ver Figura 7).

\section{Divisiones territoriales: barrios y veredas en Aguazul}

La composición barrial y veredal se ha constituido en muestra de los cambios espaciales (ver tabla 9) en relación con otros factores, como la llegada de población de zonas rurales a urbanas, el creciente volumen demográfico atraído por la actividad petrolera, la construcción de nuevos barrios con recursos propios y la recepción e inversión de regalías en infraestructura urbana, vías y vivienda de interés social (VIS), elementos relevantes en la generación de cambio espacial y de una configuración territorial diferencial.

Las actividades económicas influyen en la construcción del territorio a través de sus agentes y sus estrategias de acción por él. En vista del carácter estratégico y de la movilización de recursos de las empresas petroleras, estas recurren a las Oficinas de Relaciones con la Comunidad para negociar aspectos sociales y de acceso al territorio con los diferentes actores. Una de sus políticas ha sido la de intervenir en el territorio implantando infraestructura que les fuera útil a ellos y a la comunidad, como apertura de vías, escuelas, etc. Posteriormente, y en medio de las tensiones entre comunidad y

Tabla 9. Aguazul, crecimiento de Barrios y Veredas, 1976 - 2003

\begin{tabular}{|c|c|c|c|c|c|c|}
\hline Año & Barrios & $\begin{array}{c}\text { Crecimiento } \\
\text { relativo barrios }\end{array}$ & $\begin{array}{c}\text { Tasa } \\
\text { anual }\end{array}$ & Veredas & $\begin{array}{c}\text { Crecimiento } \\
\text { relativo veredas }\end{array}$ & $\begin{array}{c}\text { Tasa } \\
\text { anual }\end{array}$ \\
\hline 1976 & 3 & 1 & & 7 & & \\
1989 & 4 & 0,1 & 39 & 32,00 & 2,5 \\
1990 & 4 & 13 & 0,0 & 39 & 0,00 & 0,0 \\
1996 & 17 & 2,2 & 57 & 18,00 & 3,0 \\
1999 & 28 & 11 & 3,7 & 58 & 1,00 & 0,3 \\
2003 & 29 & 1 & 0,3 & 59 & 1,00 & 0,3 \\
\hline
\end{tabular}

Fuente: Elaboración propia. Basado en: Anuario Estadístico del Casanare, 1988; Diseño Programa Corredor Petrólero, 1996; Rojas, 1999:29; Gobernación del Casanare, 2009. 
empresa por la explotación de los recursos considerados propios, se induce una política de otorgar cupos laborales en sus áreas de influencia.

Aguazul contaba en 1976 con siete veredas; trece años después, en 1989, existían 39 (ver tabla 9), manteniendo la misma extensión del territorio municipal (DANE, 1998:18). Entre 1989 y 1999 se aprecian los cambios más notorios en la composición veredal del municipio. En 1996 contaba ya con 57 veredas, casi doblaba el número de veredas en solo 6 años. En los anuarios estadísticos se aprecia la "aparición" y "desaparición" de veredas sin precisar sus límites. El crecimiento en número es equivalente a la fragmentación de las unidades veredales y coincide temporalmente con el inicio de las exploraciones (Figura 5) y con los cambios en la dinámica económica impulsada por el auge petrolero, en especial, por la política laboral de la BP hacia la población veredal:

Desde hace unos 15 años la compañía tomó como política lo que se llamó Contenido Casanareño, que en resumen era hacer un Plan de Acción para darle oportunidad a Casanare que se desarrollara en: (1) Mano de obra no calificada (MONC) y calificada (MOC), en los años 90 la MONC era solo del 40 o $50 \%$, la mayoría, debido a los altos salario que paga la industria del petróleo, era de otros municipios, en especial de los petroleros o de Sogamoso, Neiva, Barranca. Inicialmente se inició con la obligación de que la MONC era del orden de $60 \%$ y se fue aumentando hasta llegar al

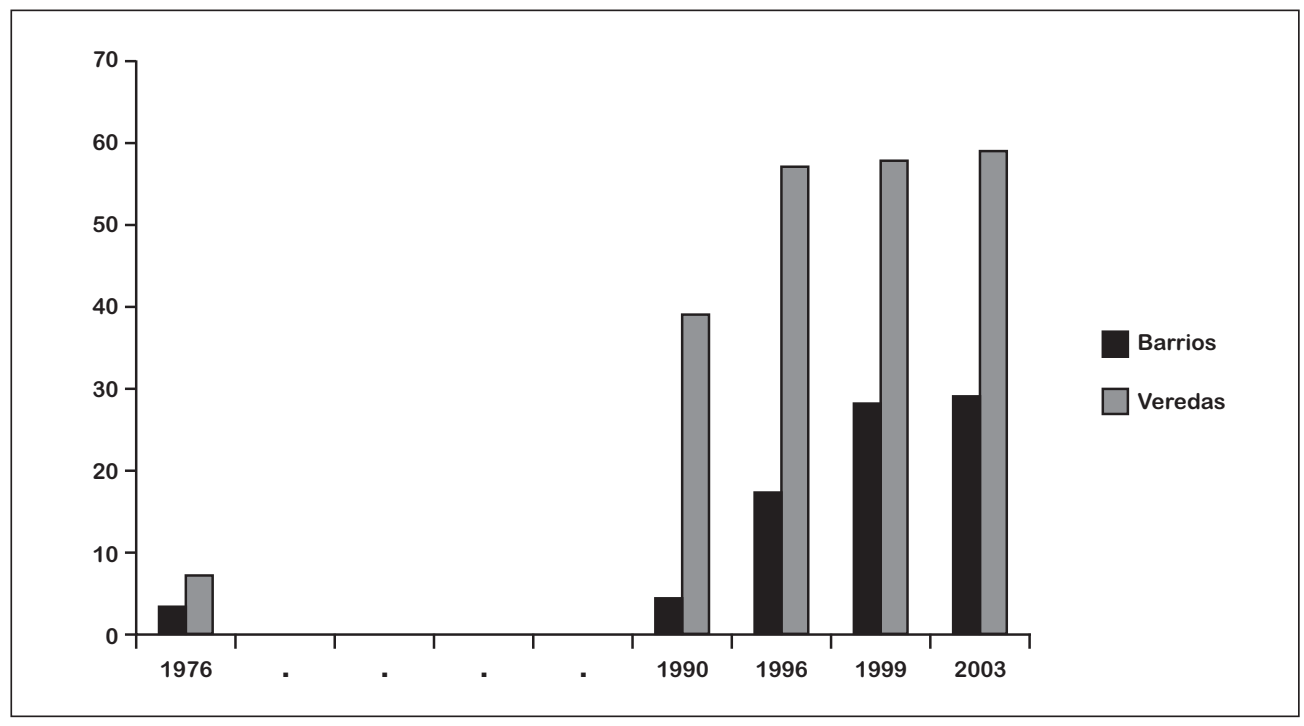

Figura 4. Crecimiento de barrios y veredas en Aguazul, 1976-2003

Fuentes: Gobernación de Casanare, Consucol, 1996, Gobernación del Casanare, 1988, Alcaldía de Aguazul, 2000. 
$100 \%$ [...]. Toda la MONC la suministran las JAC y la política dice que debe ser de la vereda donde se ejecuta el trabajo (Entrevista 4. Encargado ORC, empresa petrolera, com. per.).

Esta situación generó una fuerte disputa por los puestos de trabajo entre veredas, que produjo fragmentaciones de tipo social y político-administrativo entre la comunidad por los cupos de trabajo; uno de los testimonios encontrados en campo confirma esta afirmación:

Por ejemplo, si reventaba un pozo petrolero, por ejemplo en Bellavista, entonces la Junta Comunal de Bellavista no permitía que le dieran trabajo a los del área urbana de Aguazul, tenían que darles los contratos a ellos y a todo, y si el municipio iba a desempeñar una obra allá tenían que darle el trabajo a ellos allá (entrevista
20, antiguo habitante del municipio, líder y empresario, com. per.).

La situación del acceso a los cupos laborales redundó en nuevas formas de delimitación y disputa por el territorio, que incluyen la "desaparición" de veredas como La Cabuya, La Carbonera y La Defensa. Otras, como El Bubuy, se subdividen o fragmentan en Tesoro del Bubuy, San José del Bubuy y Rincón del Bubuy; Cunamá, en Cunamá y Plan Brisas-Plan Cumaná; Cupiagua, en Cupiagua y Alto Cupiagua; La Esmeralda, en La esmeralda y Rincón de la Esmeralda. Aparecen veredas "nuevas", como Altamira, Alto Lindo, Atalayas, Cuarto Unete, El Cerrito, El Guineo, Guadalcanal, Guaduales, Guadualito, Iguamena-Cayaguas, La Florida, La Primavera, La Vegana, La Unión, Laureles, Piñalito-Salitrico, Puente Cusiana, Retiro-Milagro,

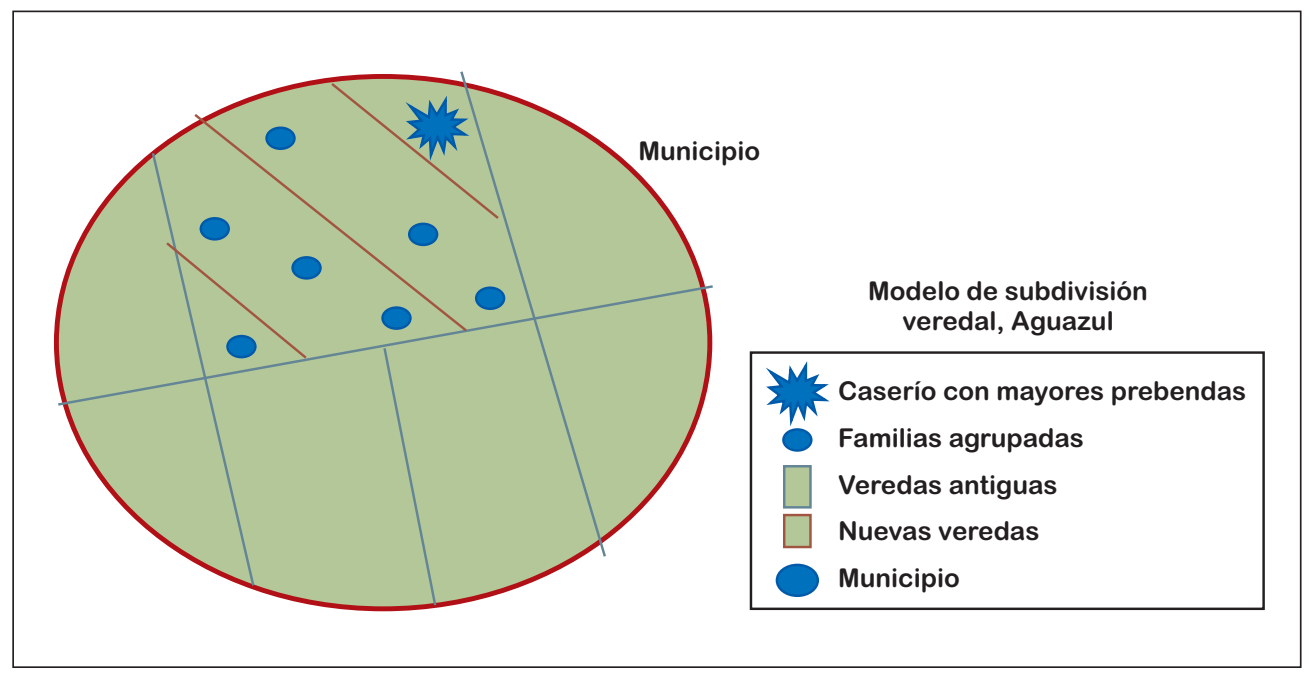

Figura 5. Modelo de fragmentación veredal en Aguazul Fuente: Elaboración propia basada en entrevistas. 
Sabanales, San Lorenzo, Sevilla y Valle Verde $^{3}$. El número de barrios en Aguazul entre los años 1976 y 1990 no varió considerablemente; sin embargo, en 1996, al igual que lo sucedido con la fragmentación y crecimiento en número de veredas, el número de barrios crece, junto al ejército de mano de obra disponible para la actividad petrolera asentado en la zona urbana.

\section{Conclusiones}

Los cambios espaciales descritos se han asociado de manera importante a la actividad petrolera, sin embargo, ambos asentamientos existían antes del auge petrolero y ya cumplían funciones de concentración de personas y servicios: Tauramena, como centro "religioso" y educativo que en su principio atrajo población estudiantil de zonas aledañas, y Aguazul, reubicado después de "la Violencia”, que se constituyó en punto de unión entre Sogamoso y el Casanare, paso obligado de ganaderos, de comerciantes y viajeros, y que además se distinguió por la producción de arroz, antes que de petróleo. En ambos casos, su nacimiento no se relaciona de forma directa con el "bum petrolero", aunque sí es clara la influencia determinante de este en su proceso de cambio.

Los modelos de las "Boomtowns" y las "Companytown", con sus características particulares, coinciden con los de Tauramena y Aguazul en cuanto a la asociación a un modelo de extractivismo, pero se diferencian en que fueron creados de forma planeada tanto para los trabajadores como para sus familias, caso muy diferente al de estos dos municipios. En los dos municipios objeto de estudio se observan algunas características diferenciales:

- No son centros urbanos planeados, existían previamente y su crecimiento no ha sido controlado. Tampoco se trata de centros "monoculturales", sino absolutamente diversos, debido al flujo migratorio que acompaña al auge petrolero.

- El alto valor de las regalías percibidas influye en el territorio; en el ámbito urbano, con la generación de obras de infraestructura y viviendas de interés social, y en el rural, con la inversión en las zonas de influencia directa, como en las veredas. Esto contrasta con la poca preparación para el manejo de recursos y de crecimiento urbano y poblacional.

- Los ejes de comunicación intermunicipal (carácter rural) son los que predominan en la configuración del tejido urbano, que en un principio se asimila a un modelo lineal que con la densificación se va compactando.

3 Este análisis se realizó a partir de la comparación de listas de composición veredal en diferentes documentos como Anuarios estadísticos y Documentos Dane, entre otros. Debido a la gran dinámica de cambio veredal y a la dificultad en la definición de los límites interveredales no fue posible encontrar información precisa que permitiera una representación cartográfica apropiada y fie a la dinámica del fenómeno. 
Los cambios visibles en el espacio aquí plasmados responden a múltiples factores; para comprenderlos fue necesario relacionarlos con las dinámicas demográficas, económicas, de inserción de la región en el mercado mundial a través de la actividad petrolera, con las tensiones y disputas ente actores en torno a la construcción territorial, como se ejemplificó con el caso de la subdivisión veredal en Aguazul. Lo que se plasma aquí es una muestra de la integralidad de la configuración territorial como proceso y también como producto de interrelaciones de poder, que se reflejan en un aspecto tan particular como los cambios espaciales. Entender estos cambios es un paso para ver las formas de ejercer y construir territorialidad, de morfología espacial y social.

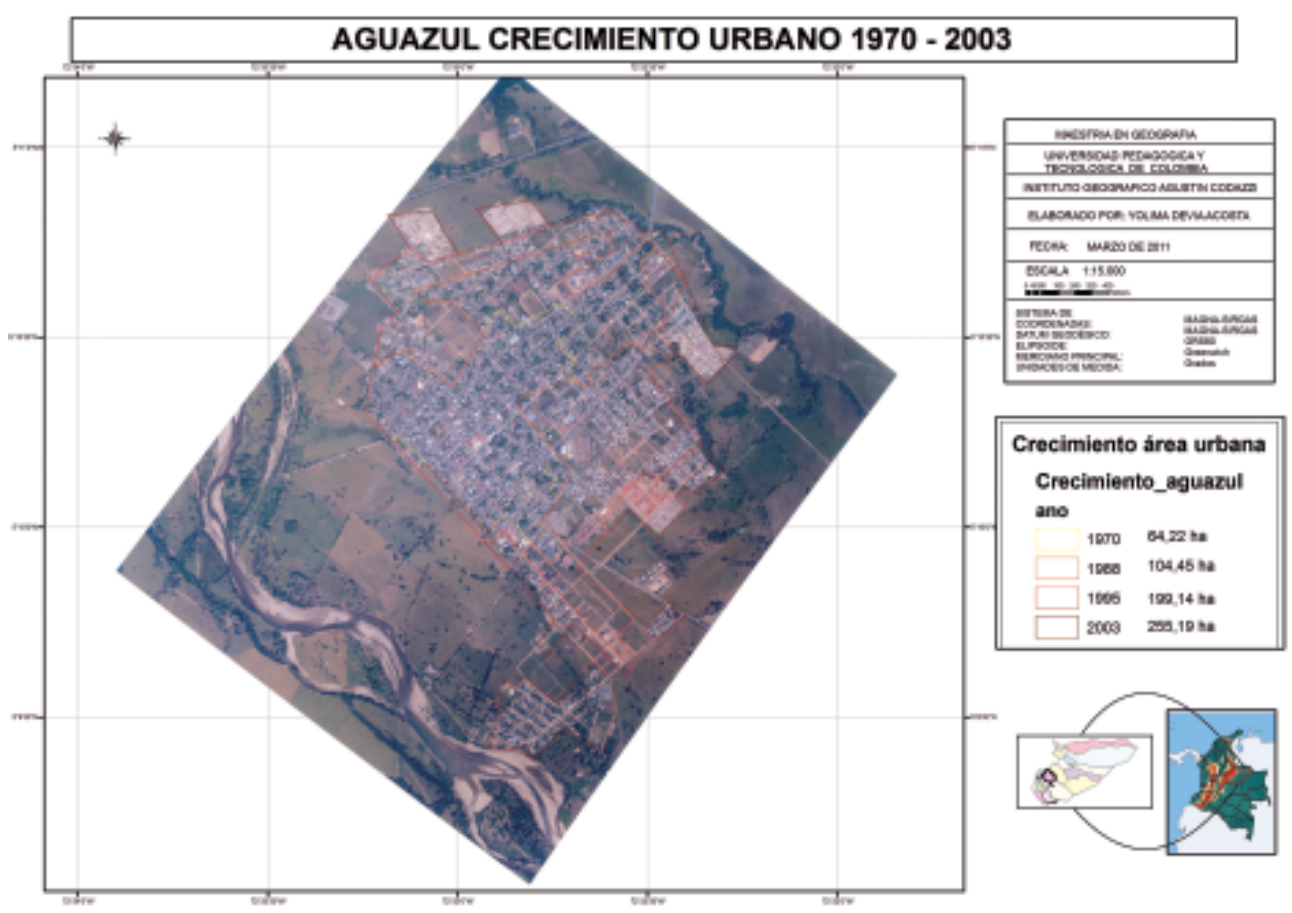

Figura 6. Dinámica de crecimiento urbano, Aguazul, 1970-2003

Fuente: Fotointerpretación sobre fotografías aéreas. 


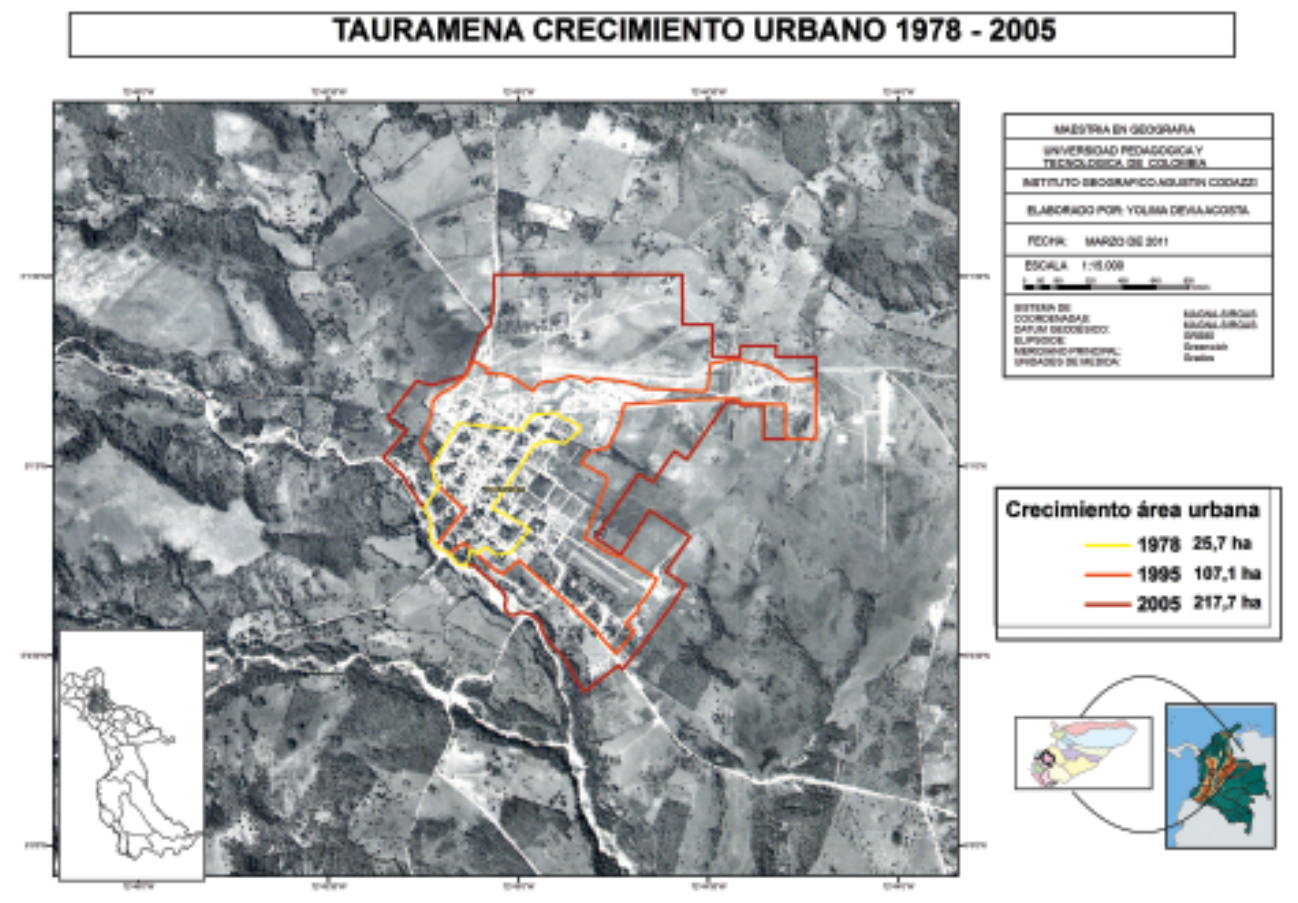

Figura 7. Dinámica de crecimiento urbano, Tauramena, 1978-2005 Fuente: Fotointerpretación sobre fotografías aéreas.

198 Claudia Yolima Devia Acosta 


\section{Literatura citada}

Alcaldía de Aguazul. (2003). Esquema de Ordenamiento Territorial.Proyecto de acuerdo. Aguazul.

Alcaldía de Tauramena. (1999). "Diagnóstico urbano funcional". En: Esquema de Ordenamiento Territorial 2000-2010.Tauramena.

Alcaldía de Tauramena. (2000). "Diagnóstico económico". En: Esquema de Ordenamiento Territorial de Tauramena, 2000-2010. Acuerdo 014, junio 21 de 2000.

Alcaldía de Tauramena-Unitrópico. (2005). Revisión, evaluación y ajuste del esquema de ordenamiento territorial. Tauramena.

Capel, H. (2002). La morfología de las ciudades I. Sociedad, cultura y paisaje urbano. Barcelona: Ediciones del Serbal.

Centro de Estudios Sociales. (2005). Diagnóstico de cultura ciudadana para el departamento de Casanare: Yopal y Aguazul. Bogotá: Universidad Nacional-Facultad de Ciencias Humanas.

DANE. (1988). Anuario estadístico de la intendencia del Casanare. Bogotá: DANE.

Dureau, F. y Flórez, C. (2000). Aguaitacaminos: las transformaciones de las ciudades de Yopal, Aguazul y Tauramena durante la explotación petrolera de Cusiana y Cupiagua. Bogotá: Uniandes y Tercer Mundo.

Garcés, E. (2003). "Las ciudades del cobre. Del campamento de montaña al modelo del hotel minero como variaciones de la Company Town". Eure 29(88): 131-148.

Gobernación de Casanare. (2009). Cifras. Obtenido octubre de 2009 desde: http:// www.casanare.gov.co/index.php?idcategoria $=1230$.

Gramling, B. y Brabant, S. (1986). "Boomtowns and Offshore Energy Impact Assessment.The Development of a Comprehensive Model". [Ciudades de crecimiento rápido debido al auge y Evaluación de impacto de la energía en el exterior. El desarrollo de un modelo comprensivo]. Sociological Perspectives, 29(2): 177-201. Obtenido en mayo de 2008 desde:

http://links.jstor.org/sici?sici $=07311214 \% 28198604 \% 2929 \% 3 \mathrm{~A} 2 \% 3 \mathrm{C} 177 \% 3$

ABAOEIA \%3E2.0.CO\%3B2-J

Perspect. geogr. Vol. 15. Año 2010, pp. 177-200 199 
Haesbaert, R. (2004). O mito da desterritorialização. Rio de Janeiro: Bertrand Brasil.

IGAC. (1999). Casanare: características geográficas. Convenio Gobernación del Casanare, Corporinoquia, Organización de los Estados Iberoamericanos, BP Exploration Company (Colombia) Ltda., Ecopetrol, Triton Colombia Inc. y Total Exploration Exploration Exprodukhe Maatchappisbu. Bogotá: IGAC.

Novoa, E. A. (2010). La metamorfosis de la cuestión espacial en Colombia. Bogotá: Universidad Nacional de Colombia, Facultad de Derecho, Ciencias Políticas y Sociales - Instituto Unidad de Investigaciones Jurídico-Sociales Gerardo Molina -UNIJUS-. 